\title{
Immunomodulatory and antioxidant effects of polysaccharides from the parasitic fungus Cordyceps kyushuensis
}

Jianya LING ( $\square$ lingjianya2014@126.com )

Shandong University https://orcid.org/0000-0002-6788-8919

Jinjuan Su

State key laboratory of Microbial Technology, Shandong University

Guoying Zhang

Shandong University of Traditional Chinese Medicine

Jing Sun

Dezhou people's hospital

Original article

Keywords: fungal-derived polysaccharide, immunomodulatory, lymphocyte, antioxidant, Cordyceps kyushuensis

Posted Date: May 6th, 2020

DOl: https://doi.org/10.21203/rs.3.rs-26190/v1

License: (c) (i) This work is licensed under a Creative Commons Attribution 4.0 International License. Read Full License 


\section{Abstract}

Ascomycete Cordyceps genus has been used as valued traditional Chinese medicines. Cordyceps kyushuensis is a unique species of Cordyceps, which parasitizes on the larvae of Clanis bilineata Walker, and its major component cordycepin and aqueous extract are known to have many pharmacological effects. However, the physiological function of water soluble polysaccharides has not been explored in detail. In this study, to resolve these doubts, we extracted and separated Cordyceps-derived polysaccharides, then evaluated the immunomodulatory and antioxidant activities. Four polysaccharide fractions were purified from Cordyceps cultured stroma by DEAE-cellulose 23 and Sephadex G-150 column chromatography. Basic structural information was elucidated on the basis of physicochemical property and spectroscopic evidences. The antioxidant activities were evaluated by DPPH radical method and protective effect of DNA damage. The qualified immunologic activities were also determined in vivo and in vitro. The polysaccharides could stimulate the proliferation of mouse splenocytes whether ConA and LPS existed or not, strengthen peritoneal macrophages to devour neutral red, and increase the content of IL-2 and TNF-a in serum. The research provides the corresponding evidence for Cordyceps polysaccharides as a potential candidate for functional foods and therapeutic agents.

\section{Introduction}

It is reported that about a total of 110,000 fungal species had been recognized (Wasser 2010). Macrofungi, also known as mushrooms, have been extensively used as foods, nutraceuticals, and medicines since time immemorial (Friedman 2016). The edible and medicinal mushrooms are recognized as one of the most important food supplements and have been recently studied for bioactive metabolites because of their vital roles in human health, nutrition, and various illnesses. Fungal-derived polysaccharides, a kind of natural biological macromolecules, recognized as "biological response modifiers", mainly derived from the mycelium, fruiting bodies, and fermentation broth of the Basidiomycetes family, and some from the Ascomycetes. Depending on their chemical composition, molecular weight, conformation, glycosidic bond, degree of branching, etc (Methacanon et al. 2005), fungal polysaccharides presented good nutritional values and pharmaceutical properties, such as immunomodulatory (Fan et al. 2018; Cheung et al. 2009; Li et al. 2019), antitumor (Rashid et al. 2011; Fisher and Yang 2002; Wu et al. 2012), antioxidant (Sun et al. 2009), hypocholesterolemic (Jin et al. 2019; Liu et al. 2019), hepatoprotective (Zhang et al. 2012), and anti-inflammatory activities (Gondim et al. 2012).

The genus Cordyceps belongs to the entomopathogenic fungi, Clavicipitaceae, Ascomycotina (Tang and Eisenbrand 1992). Cordyceps sinensis and C. militaris, have been used as traditional Chinese medicines for the effectiveness in improving lung and kidney functions, restoring health after prolonged sickness, and enhanced physical performance (Xia et al. 2017; Bi et al. 2020). Continuous attentions had been paid to Cordyceps-derived polysaccharides (Chen et al. 2015; Wang et al. 2014; Wu et al. 2012; Hu et al. 2019). Polysaccharides from the stroma and mycelia culture of Cordyceps fungus have extensive health effects and pharmacological activities, such as stimulating the innate and adaptive immune responses, 
activated macrophages production (Chiu et al. 2014; Meng et al. 2014). C. kyushuensis is a unique species of Cordyceps, and it is worth of further investigation. As far as we know, the only host of $C$. kyushuensis is the larvae of Clanis bilineata walker (Shimizu 1994). Two polysaccharides purified from the cultured stroma of $C$. kyushuensis were reported previously by our group, showed remarkably antioxidant effects by assays of various antioxidant in vitro systems (Zhang et al. 2015).

Up to now, there are only a few research papers on purification of polysaccharides from $C$. kyushuensis and their immunostimulatory activity. Therefore, in the present study, four other water-soluble polysaccharides of $C$. kyushuensis were extracted, purified and preliminarily characterized. Moreover, immune regulation and antioxidant properties of the fractions were also evaluated in vitro and in vivo. The research would serve as a good foundation for further investigation, development and industrial application of Cordyceps-derived polysaccharides in functional food and therapeutic agents.

\section{Materials And Methods}

\section{Materials and reagents}

The anamorph strain JY1A of $C$. kyushuensis, originally isolated from fresh natural specimen, was confirmed by means of both morphological and molecular methods, and conserved by our lab. Cultured C. kyushuensis grew on solid rice medium and was obtained after about 90 days. The dried stroma was shattered to powder (80 mesh) for further experiment. DEAE-cellulose 23 and Sephadex G-150 were purchased from Amersham Biosciences (Uppsala, Sweden). The standard monosaccharide (D-mannose, D-galactose, D-arabinose, D-fructose, L-rhamnose, D-glucuronic acid, D-glucosamine, D-galactosamine), TFA, PMP, LPS and ConA were obtained from Sigma-Aldrich (St. Louis, MO, USA). The RPMI-1640 medium and fetal bovine serum was provided by Gibco (Vienna, NY, USA). All other chemicals and solvents used were of analytical grade and obtained from Sinopharm (Shanghai, China).

\section{Purification of polysaccharides}

The extraction of $300 \mathrm{~g}$ stroma powder was carried out three times, each time with $3 \mathrm{~L}$ distilled water at $90{ }^{\circ} \mathrm{C}$ for $2 \mathrm{~h}$. The mixtures were concentrated to one-third volume and precipitated by adding four volume of $95 \%$ ethanol ( $\mathrm{v} / \mathrm{v})$ and kept at $4{ }^{\circ} \mathrm{C}$ for overnight. The precipitate was collected and washed with $95 \%$ ethanol, acetone, and ethyl ether, respectively. The resulting fraction was dialyzed in cellulose membrane tubing (exclusion limit $3500 \mathrm{Da}$ ) against de-ionized water and lyophilized. Protein was removed by Sevag method (Matthaei et al. 1962). Crude polysaccharide was preliminarily separated by sub-fractionated with gradient final concentrations of ethanol (15\%,30\%, 50\% and $95 \%)$. The fraction at final concentration of $50 \%$ ethanol, named as CKPS, was obtained by lyophilization, and selected for further study. CKPS powder $(100 \mathrm{mg}$ ) was dissolved in $2 \mathrm{~mL}$ water, the supernatant was applied to a DEAE-23 column $(50 \times 2.0 \mathrm{~cm}$ i.d.), which was eluted with water and followed by a 4-step gradient of 0-0.32 M NaCl $(0.06,0.1,0.16$ and $0.32 \mathrm{M})$. Guided by the phenol-sulfuric acid method, the $\mathrm{NaCl}$ eluting fraction with high content of sugar was collected, dialyzed, lyophilized, and purified by Sephadex G-150 column $(80 \times 2.0 \mathrm{~cm}$ i.d. $)$. 


\section{Analysis of physicochemical properties}

Total sugar content was determined by Phenol-sulfuric acid method (Chaplin and Kennedy 1994) with glucose as the standard. Protein concentration was measured with a Bradford protein assay kit (Beyotime, Shanhai, China). Sulfate content was evaluated using the barium chloride-gelatin method (Kawai et al. 1969) and the content of uronic acid was assessed by the method of m-hydroxydiphenyl using galacturonic acid as standard (Bitter and Muri 1962).

Identification and quantification of monosaccharide was carried out by HPLC method (Sun et al. 2009) with some modification. The polysaccharide $(5 \mathrm{mg})$ was hydrolyzed with $2 \mathrm{M}$ TFA at $120^{\circ} \mathrm{C}$ for $4 \mathrm{~h}$ in a sealed-tube fulfilled with $\mathrm{N}_{2}$. Then excessive acid was removed by methanol. The dried sample was dissolved with solution containing $0.3 \mathrm{M}$ aqueous $\mathrm{NaOH}(0.5 \mathrm{~mL})$ and $0.5 \mathrm{M}$ methanol solution of PMP $(0.5 \mathrm{~mL})$, and incubated at $70^{\circ} \mathrm{C}$ for $100 \mathrm{~min}$, then neutralized with $0.5 \mathrm{ml}$ of $\mathrm{HCl}(0.3 \mathrm{M})$. The resulting solution was extracted by chloroform for three times. The aqueous layer was filtered through a $0.22 \mu \mathrm{m}$ nylon membrane (MSI, Westbor-ough, MA, USA), and injected in to a Kromasil $100-\mathrm{C}_{18}$ column $(250 \times 4.6$ $\mathrm{mm}$ i.d., $5 \mu \mathrm{m}$ ) at $260 \mathrm{~nm}$ and at a column temperature of $25^{\circ} \mathrm{C}$. The mobile phase, a solution of $0.02 \mathrm{M}$ phosphate buffer (pH 6.7): acetonitrile= 80:20 (v/v), was eluted at a flow rate of $0.9 \mathrm{~mL} / \mathrm{min}$. Identification of the target compounds was based on comparison with reference sugars. Calculation of the molar ratio of the monosaccharide was carried out on the basis of the peak area of the monosaccharide.

Homogeneity and absolute measure of molecular weight of the purified fractions were obtained by HPSEC (Agilent Technologies, 1200 series LC system, St. Clara, CA, USA) coupled with MALLS (Wyatt Technology DAWN HELEOS II, St. Barbara, CA, USA) at $690 \mathrm{~nm}$. The sample was dissolved with mobile phase $(5 \mathrm{mg} / \mathrm{mL})$ and filtered through a $0.22 \mu \mathrm{m} \mathrm{MSI} \mathrm{nylon} \mathrm{syringe} \mathrm{filter} \mathrm{before} \mathrm{injection.} \mathrm{A} \mathrm{serial} \mathrm{column}$ which combined TSK-Gel G-6000 PWXL (300×7.8 mm i.d., Tokyo, Japan) with TSK-Gel G-5000 PWXL columns was then employed to separate the samples at $30^{\circ} \mathrm{C}$. The pre-degassed $0.2 \mathrm{M} \mathrm{NaCl}$ aqueous solution was applied as the elution buffer at a flow-rate of $0.6 \mathrm{~mL} / \mathrm{min}$. Three injection operations of the polysaccharide were performed and molecular mass values were determined by averaging these results.

FTIR spectra were recorded in the region $4000-400 \mathrm{~cm}^{-1}$ on Thermo Nicolet 20sx spectrometer at $4 \mathrm{~cm}^{-1}$ resolution. The samples were blended with $\mathrm{KBr}$ powder, grounded and pressed into a $1 \mathrm{~mm}$ pellets. The

${ }^{1} \mathrm{H}$ and ${ }^{13} \mathrm{C}$ NMR spectra were recorded on a Brucker AM-400 MHz NMR spectrometer (Rheinstetten, Germany) at $25^{\circ} \mathrm{C}$. The polysaccharide sample $(25 \mathrm{mg})$ was exchanged 3 times with DMSO-d6 upon freeze-drying, re-dissolved in $0.5 \mathrm{~mL}$ DMSO- $d 6$, and centrifuged prior to analysis.

\section{Vertebrate Animal Study Methods}

Animals care, feeding, housing, and grouping

A total 60 male healthy Kunming mice ( 8 weeks old, $20.0 \pm 2.0 \mathrm{~g}$ ), SPF grade, were purchased from Laboratory animal center of Shandong University. The mice were housed on a 12-h-dark/12-h-light cycle 
at $22 \pm 1{ }^{\circ} \mathrm{C}$ and $50-60 \%$ relative humidity, free to access to standard laboratory rodent diet and water during the experiments. All procedures involving animal study were approved by the Ethics Committee of School of Life Science of Shandong University. After being adapt to the environment for one week, the mice were randomly divided into test and control groups (10 for each).

Assay of immunity activity in vivo

The polysaccharide samples were dissolved in physiological saline, and given intraperitoneally to mice at doses of $10 \mathrm{mg} / \mathrm{kg} / \mathrm{d}$ for 7 consecutive days. Control group was treated with $0.2 \mathrm{~mL}$ physiological saline instead of the polysaccharide solution. The mice were sacrificed via cervical vertebra dislocation $24 \mathrm{~h}$ after the last administration. The spleen was removed aseptically and then was placed in aseptic PBS buffer. Spleen cells were harvested by gently mincing and grinding the spleen fragment through sterilized meshes (200 meshes), and centrifuged at $3000 \mathrm{rpm} / \mathrm{min}$ at $4{ }^{\circ} \mathrm{C}$ for $5 \mathrm{~min}$. After red blood cells were removed by erythrocyte lysis buffer, the remaining cells were washed twice and suspended to $1 \times 10^{6}$ cells/mL by RPMI 1640 complete medium containing $10 \%$ fetal bovine serum. The Spleen cells (100 $\mu \mathrm{L} /$ well) were placed in a 96-well plate with a total volume of $200 \mu \mathrm{L}$ per well, in the presence of mitogen $\left(5.0 \mu \mathrm{g} / \mathrm{mL}\right.$ ConA, or $10.0 \mu \mathrm{g} / \mathrm{mL}$ LPS, final concentration), or RPMI 1640 medium, and incubated at $37{ }^{\circ} \mathrm{C}$ in a humidified $5 \% \mathrm{CO}_{2}$ incubator for $48 \mathrm{~h}$. Cells proliferation was determined by CCK-8 assay (Dojindo, Kumamoto, Japan).

The blood samples were obtained from eye-orbital sinus under light ether anaesthesia prior to being sacrificed. After centrifugation at $2000 \times \mathrm{g}$ for $10 \mathrm{~min}$, the serum samples were collected. The IL-2 and TNF-a concentration were measured with Mouse IL-2 or TNF-a Sunny ELISA kit (MultiSciences, Hangzhou, China) according to the indication of the manufacturer.

Assay of immunity activity in vitro

8-12 weeks old SPF mice were sacrificed by cervical dislocation, spleens were collected under aseptic conditions in RPMI-1640, and spleen cells were prepared and adjusted to $1 \times 10^{6}$ cells $/ \mathrm{mL}$. $100 \mu \mathrm{L} /$ well of splenocyte suspension were seeded into a 96-well culture plate, and mixed with $100 \mu \mathrm{L}$ polysaccharide solutions $(62.5,125,250,500 \mu \mathrm{g} / \mathrm{mL}$, final concentration, respectively) in triplicate. The RPMI 1640 medium was added as blank control, ConA $(5.0 \mu \mathrm{g} / \mathrm{mL}$, final concentration), and LPS $(10.0 \mu \mathrm{g} / \mathrm{mL}$, final concentration) was used as positive control, respectively. The plate was incubated at $37^{\circ} \mathrm{C}$ in a humidified $5 \% \mathrm{CO}_{2}$ incubator for $48 \mathrm{~h}$. The viable cells were determined at $450 \mathrm{~nm}$. Cell proliferation rate (\%) was calculated as the absorbance of sample-treated cells divided by the absorbance of control cells. Cell viability of the control group was $100 \%$.

The resident macrophages of mice were harvested by peritoneal lavage, and the cells were subsequently cultured in RPMI 1640 complete medium and diluted to a density of $2 \times 10^{6}$ cells $/ \mathrm{mL}$. The purity of macrophages was tested by adherence. Macrophage suspension ( $100 \mu \mathrm{L} /$ well) was pipetted into a 96-well culture plate and incubated for $3 \mathrm{~h}\left(37^{\circ} \mathrm{C}, 5 \% \mathrm{CO}_{2}\right)$. The adherent macrophages were 
washed twice by complete medium and then incubated with $100 \mu \mathrm{L}$ various concentrations $(125,250$, $500,1000 \mu \mathrm{g} / \mathrm{mL}$ ) of polysaccharides for $24 \mathrm{~h}$. The stimulated cells were washed twice by PBS, and 100 $\mu \mathrm{L}$ neutral red $(0.1 \%, \mathrm{w} / \mathrm{v})$ was used to assess the phagocytosis. The plate was incubated for $3 \mathrm{~h}$. After the removal of un-phagocytized neutral red by PBS, $200 \mu \mathrm{L}$ cell lysate (the volume ratio of acetic acid to ethanol was 1:1) was added in and kept for $3 \mathrm{~h}$. The OD value of each well was read at $540 \mathrm{~nm}$ using the Model 550 Microplate Reader (Bio-Rad, Hercules, CA, USA). DMEM medium and LPS $(10 \mu \mathrm{g} / \mathrm{mL})$ were used as the blank and positive control, respectively.

Dislocation euthanasia method

At the end of the experiments, the cervical vertebrae of all surviving animals were dislocated by external force, and the spinal cord was severed to make them die painlessly.

\section{DPPH radicals scavenging assay}

The radical scavenging effects of the polysaccharides were estimated by using DPPH free radicals method (Blois 1958). DPPH solution $(50 \mu \mathrm{L}, 0.1 \mathrm{mM})$ in $50 \%$ ethanol was added in 96 -well plate with equivalent aliquot sample solution at different final concentrations $(0.5,1,1.5,2,2.5 \mathrm{mg} / \mathrm{mL})$. The reaction solution was shaken vigorously and incubated at room temperature for $30 \mathrm{~min}$, and the absorbance at $517 \mathrm{~nm}$ was measured. VC was used as a positive control. The DPPH scavenging rate $(R)$ was calculated as the following formula, $R(\%)=[1-(\mathrm{As}-\mathrm{Ai}) / \mathrm{A} 0] \times 100$. As indicated as absorbance of sample or VC. Sample reference solution, which contained equivalent $50 \%$ ethanol instead of the DPPH solution, was recorded as $A_{i}$, while distilled water instead of sample was used for the blank $A_{0}$. All tests were performed in triplicate and the mean of Abs was used in the equation above.

\section{Determination of DNA damage protective effect}

DNA damage protection activities of polysaccharides were determined with pUC19 plasmid DNA, isolated from Escherichia coli DH5a by SanPrep column plasmid mini-preps kit (Sangon Biotech, Shanhai, China). pUC19 plasmid was damaged by $\mathrm{H}_{2} \mathrm{O}_{2}$ and UV treatment using the method of Yang (Yang et al. 2014). Rutin was used as a positive control. Different structural or conformational forms of plasmid DNA were separated by electrophoresis. The reaction mixture $(10 \mathrm{~mL})$ contained $3 \mathrm{~mL}$ of plasmid DNA, $5 \mathrm{~mL}$ of 5 $\mathrm{mg} / \mathrm{mL}$ polysaccharide or $0.4 \mathrm{mg} / \mathrm{mL}$ rutin, $1 \mathrm{~mL}$ of $10 \mathrm{mmol} / \mathrm{mL} \mathrm{H}_{2} \mathrm{O}_{2}$ and $1 \mathrm{~mL}$ of water. The mixtures were located in super clean bench with ultraviolet lamp $(20 \mathrm{~W})$. After UV irradiation lasted for $5 \mathrm{~min}$ at room temperature, reaction samples along with 10xgel loading dye were analyzed on a $1 \%$ agarose gel in TBE buffer at $\mathrm{pH} 8.0$ for $30 \mathrm{~min}(100 \mathrm{~V})$.

\section{Statistical analysis}

All bioassay results were expressed as means \pm standard deviation (SD). The experimental data were subjected to an analysis of variance (ANOVA) for a completely random design. A probability of $P<0.05$ and $P<0.01$ was considered as significant. 
Add your materials and methods here.

\section{Results}

\section{Isolation and purification}

The crude polysaccharide was obtained by water extraction, ethanol precipitation, deproteinization and lyophilization. As shown in Fig. 1A showed that $50 \%$ ethanol portion (CKPS) with a yield of $4.86 \%$ was further fractionated on a DE-23 column eluting with de-ionized water, and different concentrations of stepwise $\mathrm{NaCl}$ solution $(0.06,0.1,0.16$ and $0.32 \mathrm{M})$. Guided by the phenol-sulfuric acid method, The $\mathrm{NaCl}$ elutes F1, F2, F3 and F4 were further purified by Sephadex G-150 column, respectively. Four resulting fractions named as CKPS-1, CKPS-2, CKPS-3 and CKPS-4 (Fig. 1B) were collected and treated for followup research.

\section{Physicochemical characterization}

Positive response to the Bradford method, and the adsorption detected by UV spectrum at $280 \mathrm{~nm}$, indicated the presence of protein. The results proved that CKPS-1, CKPS-2, CKPS-3 and CKPS-4 all contained minor amounts of protein $(0.45,1.07,1.53$ and $4.34 \%$, respectively) and uronic acid $(0.51,0.77$, 0.86 and $1.22 \%$, respectively), and did not have any sulfate ester. Uronic acid was found in all four fractions, which suggested that these fractions were starch-like polysaccharides. The total carbohydrate contents of the samples were $84.35,77.33,84.29$, and $78.22 \%$, respectively. Neutral monosaccharide constitutions of the polysaccharides were analyzed by reversed-phase HPLC. CKPS- 1 was mainly composed of Fru, Man, Glu and Gal with molar ratios of 1:0.92:1.09:0.72. CKPS-2, CKPS-3 and CKPS-4 was consisted of Fru, Man and $\mathrm{Gal}$ in a molar percentage of 1:0.63:0.61, 1:1.65:1.4 and 1:2.06:1.97, respectively. Results showed that fructose, mannose and galactose were the main monosaccharide components in four samples with different molar ratios, and glucose was only found in CKPS-1, strongly indicating that the polysaccharides were heterogeneous. Large amounts of fructose components were found in both $50 \%$ ethanol and $90 \%$ ethanol precipitates (Zhang et al. 2015) of C. kyushuensis, which is quite different from the reports on polysaccharide of other Cordyceps species. HPSEC equipped with MALLS was considered to be a powerful, effective and reliable technique for determining molecular characteristics of macromolecules without any calibration standard. Single and symmetrical peaks indicated that the four fractions were homogeneous polysaccharides. The Mw of the purified polysaccharides was estimated to be $7153,5945,5643$ and $5642 \mathrm{kDa}$, respectively. The IR spectra of four fractions exhibited the characteristic absorption of polysaccharides. All the fractions had similar infrared absorption bands indicating similarities in their structural features. The strong and broad peak between $3600 \mathrm{~cm}^{-1}$ and $3200 \mathrm{~cm}^{-1}$ was due to the stretching vibration of O-H. The bands at 2924 and $2854 \mathrm{~cm}^{-1}$, which corresponded to $\mathrm{C}-\mathrm{H}$ stretching vibration in $-\mathrm{CH}_{2}$ and $-\mathrm{CH}_{3}$ groups (usually present in hexoses, like glucose or galactose, or deoxyhexoses like rhamnose or fucose), is further proved that what we are 
dealing with is polysaccharide containing glucuronic acid (Leandro et al. 2003). The band at $1645 \mathrm{~cm}^{-1}$ corresponds to the stretching vibration of the carbonyl bond that is a part of amide group and the band at $1545 \mathrm{~cm}^{-1}$ is related to the $\mathrm{N}-\mathrm{H}$ bending vibration of the same group. Occurrence of these two vibrations due to amide group indicates the presence of protein. The signal at $1408 \mathrm{~cm}^{-1}$ could be assigned to stretch vibration of $\mathrm{C}-\mathrm{O}$ within $\mathrm{COOH}$ (Kacurakova et al. 2000). The signal at $1225 \mathrm{~cm}^{-1}$ accounted for asymmetric stretching vibration of sulfate group (Zhang et al. 2005). The absorptions in the range of 1000-1200 $\mathrm{cm}^{-1}$, attributed to the stretching vibrations of $\mathrm{C}-\mathrm{O}-\mathrm{C}$ and $\mathrm{C}-\mathrm{O}-\mathrm{H}$, were observed. It indicated the strong absorptions at around $1048 \mathrm{~cm}^{-1}$ due to stretching vibration of the pyranose ring. In addition, the absorption band at $811 \mathrm{~cm}^{-1}$ and $880 \mathrm{~cm}^{-1}$ indicated the presence of $d$-mannopyranose and galactose units (Shingel 2002).

The anomeric protons from each monosaccharide can give recognizable signals depending on $\alpha$ - or $\beta$ configurations. Most of a-anomeric protons usually appear in the $5-6 \mathrm{ppm}$ region in ${ }^{1} \mathrm{H}$ NMR while most of the $\beta$-anomeric protons in the $4-5 \mathrm{ppm}$ range (Cui 2006). The signals at 5.53 and $5.46 \mathrm{ppm}$ of Fig. $2 \mathrm{~A}$ were attributed to a-configuration pyranose units of CKPS-1. The resonance at $4.91 \mathrm{ppm}$ may be attributed to glucosyl residues (Seymour 1979), and ${ }^{1} \mathrm{H}$ signals at $4.53 \mathrm{ppm}$ conformed to the $\beta$ - form of D-galactopyranosyl residues. The chemical shifts from 3.4 to $4.2 \mathrm{ppm}$ were assigned to protons of C-2C- 6 of hexose glycosidic ring (Chauveau et al. 1996). Thus there were possibly both a- or $\beta$-type glycosidic linkages in CKPS-1. In a ${ }^{13} \mathrm{C}$ spectrum, the signals derived from a-anomeric carbons usually appear in the 95-101 ppm region while most of the $\beta$ - anomeric carbons will appear in the range 101-105 ppm (Cui 2006). The major resonance in the anomeric region occurs at $97-101 \mathrm{ppm}$ rather than at $90 \mathrm{ppm}$ of Fig. 2B, indicating that $\mathrm{C}-1$ of a-monosaccharide residue is linked (Uzochukwu et al. 2002). The signal at $172.79 \mathrm{ppm}$ was due to carboxyl resonance signal of uronic acid, which was consistent with the IR results. As judged by the absence of signals within $\delta 82-88$, all sugar residues were in the pyranose form. The NMR data of other three fractions were similar with those of CKPS-1 (result not shown). The detail structural features of the four polysaccharides should be further investigated by 2D NMR, periodate oxidation, and methylation analysis.

\section{Assay of immunity activity in vivo}

In this study, no deaths and other clinical strange were observed throughout the experimental period. Lymphocytes are the key effector cells of mammalian immune system. Proliferation of splenocytes is an indicator of immune activation, being related to immunity improvement of T-lymphocyte or B-lymphocyte (Zhao et al. 2014). Effects of CKPS-1, CKPS-2, CKPS-3 and CKPS-4 on splenocyte proliferation with or without mitogen (ConA or LPS) were shown in Fig. 3. Spleen lymphocyte proliferation induced by ConA in vivo has been used to evaluate T lymphocyte activity, while that induced by LPS has been used to examine B lymphocyte activity. The data of Fig. $3(A)$ and $(B)$ proved that, with the administration of the four polysaccharides at the doses of $10 \mathrm{mg} / \mathrm{kg}$, the splenocyte proliferation induced by ConA or LPS was 
significantly enhanced $(P<0.01)$, respectively. Fig.3C demonstrated that four polysaccharides still stimulated lymphocyte proliferation even without mitogenic stimuli (ConA or LPS), the experiment results were markedly higher than the control medium group $(P<0.01)$. The present data also indicated that the effect of CKPS-2 on the proliferation of mixed lymphocytes (Fig. 3C) and B lymphocytes induced by LPS (Fig. 3B) was greater than that of the other three components, while CKPS-4 had a stronger effect on the proliferation of $\mathrm{T}$ lymphocytes induced by ConA (Fig. 3A).

The IL-2 and TNF-a expression levels were measured to determine the stimulation properties of immune response of the purified polysaccharide fractions. The mice blood samples were taken from orbit at the 24 th hour after the last administration, the serum samples were collected and ready to determine IL-2 and TNF-a level by extrapolation from cytokine standard curve, according to the manufacturer's protocol. As shown in Fig. 4A, compared with the control group, the stimulating effects on secretion of TNF-a was strongly enhanced by all the four fractions $(P<0.01)$. The IL-2 expression levels of Fig. 4B were found to be elevated by the polysaccharides CKPS-1, CKPS-2 and CKPS-3 $(P<0.05)$. Additionally, CKPS-4 significantly promoted the secretion of IL-2 in serum $(P<0.01)$. IL-2 is essential for the growth, proliferation, and differentiation of $\mathrm{T}$ cells, and is produced by $\mathrm{T}$ cells normally during an immune response (Malek 2008). TNF-a is a cytokine with tumor necrosis activity that is secreted mainly by macrophages and has been recognized as an important host regulatory molecule (Vilcek and Lee 1991). The experiment data demonstrated that the four polysaccharides could enhance the immune function by promoting cytokine expression levels for both T-lymphocytes and peritoneal macrophages in vivo.

\section{Assay of immunity activity in vitro}

By performing the CCK-8 assay, the effects of CKPS on normal (without mitogen) and mitogen-induced splenic lymphocyte proliferation were investigated in the final dose range of $62.5-500 \mu \mathrm{g} / \mathrm{mL}$. As shown in Fig. 5, both ConA and LPS could greatly stimulate lymphocyte proliferation compared with the blank. Compared with the mitogen control, CKPS-4 had excellent activities on normal proliferation $(P<0.01)$. CKPS-1, CKPS-3 and CKPS-4 exhibited significant stimulation on normal proliferation at the final concentration of $62.5-500 \mu \mathrm{g} / \mathrm{mL}(P<0.01)$, but the promotion on the proliferation of lymphocytes had not shown a dose-dependent suppressive effect. At the lowest concentration of $62.5 \mu \mathrm{g} / \mathrm{mL}$, the proliferation rate of CKPS-2 was significantly higher than that of ConA or LPS, however, in the range of $250-500 \mu \mathrm{g} / \mathrm{mL}$, the high concentration of CKPS-2 did not show stimulation effect on normal proliferation $(P>0.05)$.

One of the most distinguished features of activated macrophages is an increase in phagocytosis. The CKPS fractions were evaluated with regard to the effect on the phagocytic activity of macrophages using a neutral red uptake assay. As seen in Fig. 6, each fraction had various enhancing effects on macrophage phagocytosis in the dose range of $62.5-500 \mu \mathrm{g} / \mathrm{mL}$. The phagocytic indexes of macrophages under the sample treatments all exceeded 1.0. Compared with the blank control, the fractions could considerably stimulate the phagocytosis of macrophages $(P<0.05$ or $P<0.01)$ after administration, as well as LPS 
action $(10 \mu \mathrm{g} / \mathrm{mL}, P<0.01)$. Macrophages played an important role in immune system and could phagocytose aging cells, necrotic tissues, malignant cells and pathogens invading the body, and production of cytokines. The phagocytosis of macrophages was thought as one of the most important indicators of the body's non-specific immunity (Thambiraja et al. 2015; Schepetkin and Quinn 2006; Laskin 2009). Our present results proved that the benefit effect of the polysaccharides on immune and inflammatory diseases might be partly attributed to the improvement of defective or deficient phagocytosis of macrophage.

\section{Antioxidant properties}

Natural antioxidants are known to play an important role against various diseases and aging processes. Polysaccharides were generally considered to have potential antioxidant activity. Thus it is essential to determine the antioxidant capacities of four fractions from the stroma of $C$. kyushuensis. DPPH radical methods were often conducted to evaluate the free radical scavenging ability of natural compounds (Amarowicz et al. 2004). As a stable free radical, DPPH showed the maximum absorption at $517 \mathrm{~nm}$ with violet color due to its odd electron. When DPPH encountered antioxidant scavengers, the resulting decolorization was stoichiometric with respect to the ability to bleach the DPPH radical. The scavenging effect was measured and shown in Fig.7A. All the polysaccharide fractions showed good scavenging effect against DPPH radical in a dose-dependent manner at each concentration level. The scavenging ratio at the highest concentration of CKPS-3 and CKPS-4 were $63.5 \%$ and $59.7 \%$, respectively. And compared with other samples, especially CKPS-4 had much stronger antioxidant activity even at the low concentration of $1 \mathrm{mg} / \mathrm{mL}$.

The protective effects of the polysaccharides on the damage induced by co-action of $\mathrm{H}_{2} \mathrm{O}_{2}$ and UV were studied on pUC 19 plasmid. Figure 7 (B) demonstrated that the electrophoretic pattern of DNA after UV photolysis of $\mathrm{H}_{2} \mathrm{O}_{2}(2.5 \mathrm{mmol} / \mathrm{L})$ in the absence or presence of CKPS-1 to CKPS-4, and rutin. DNA derived from pUC19 plasmid showed the band corresponding to the native form of supercoiled circular DNA (Sc DNA) on agarose gel (Lane 7). After the UV irradiation of DNA with $\mathrm{H}_{2} \mathrm{O}_{2}$, the graph of Lane 6 proved the result of the cleavage of Sc DNA to open circular form (Oc DNA) (Kumar et al. 2004). With the addition of rutin and CKPS-1 to CKPS-4, Lanes 1-5 revealed the protection effect of the polysaccharides to the damage of native Sc DNA. Lane 2 and Lane 3 of the gel showed clearly Sc DNA band, which indicated CKPS-1 and CKPS-2 had a relatively stronger capacity to suppress the formation of Oc DNA than other polysaccharides (Lane 4 and Lane 5). The positive control of rutin (Lane 1) had almost the same protective effect. Cordyceps-derived polysaccharides of CKPS-1 and CKPS-2 could be proved to reduce the damage of $\cdot \mathrm{OH}$ generated by UV-photolysis of $\mathrm{H}_{2} \mathrm{O}_{2}$ produced DNA strand scission.

\section{Discussion}


It has been reported that the immune response to fungal polysaccharide mixture may differ from that observed with purified ones (Snarr et al. 2017), and as we know, the presence of other compounds, such as proteins, polyphenols and lipids, can affect the biological activity of the fungal components. Purification and structural characterization of fungal polysaccharides is thus very important for their further application as selective and effective immune modulators (Baeva et al. 2019). The present study was undertaken to elucidate the antioxidant and immune stimulatory activities of the polysaccharides from the stoma of $C$. kyushuensis. Four water soluble homogeneous polysaccharide fractions were isolated at final ethanol concentration of $50 \%$ and purified by column chromatography. Preliminary structural characterizations were conducted, and DPPH scavenging activity and protection to DNA damage in vitro were carried out to evaluate the antioxidant potential of these fractions. The four polysaccharides could significantly enhance the splenocyte proliferation with or without mitogen (ConA or LPS) in vivo and in vitro. The effects on the production of cytokines IL-2 and TNF-a were investigated. The results showed that the levels of serum IL-2 and TNF-a was increased significantly by the fractions administration compared with those of control group, suggesting the physiological effect of the polysaccharides were implemented by increasing the immune response. Moreover, the tests of macrophage phagocytosis offered demonstrative evidence that these polysaccharides could effectively activate macrophages response. The results indicated that the polysaccharides of $C$. kyushuensis could be applied to the potential health and functional food source. This may provide new strategies for the discovery of effective and safe approaches for cancer treatment from natural resources.

\section{Abbreviations}

CKPS, Cordyceps kyushuensis polysaccharide; ConA, concanavalin A; DPPH, 1,1-diphenyl-2picrylhydrazyl; HPSEC, high performance size exclusion chromatography; IL-2, interleukin-2; LPS, lipopolysaccharide; MALLS, multi-angle laser light scattering; PMP, 1-phenyl-3-methyl-5-pyrazolone; SPF, specific pathogen free; TFA, trifluoroacetic acid; TNF-a, tumor necrosis factor-alpha; VC, vitamin C; $\mathbf{M w}$, weight-average molecular weight;

\section{Declarations}

\section{Acknowledgements}

We would like to thank Chengjia Zhang and Caiyun Sun of Core facilities for life and environmental sciences of Shandong University for technical assistance. The authors appreciate their help in earnest.

\section{Author's contributions}

JL supervised, conceived and designed the experiments. JS and GZ conducted experiments. 
All authors analyzed data. JL and GZ wrote the manuscript. All authors read and approved the manuscript.

\section{Funding}

This work was supported by the National Natural Science Foundation of China (Grant No. 21877075 and 21807066), Key Research and Development Program of Shandong Province (Grant No. 2019GSF107003) and Natural Science Foundation of Shandong Province (Grant No. ZR2015CM028).

\section{Availability of data and materials}

The authors declare that all data supporting the findings of this study are available from the corresponding authors upon request.

\section{Ethics approval and consent to participate}

All experimental procedures involving animal study were approved by the Ethics Committee of School of Life Science of Shandong University.

\section{Consent for publication}

All authors read the manuscript and expressed their consent for publication.

\section{Consent to participate}

Not applicable.

\section{Competing interests}

The authors declare that have no competing interests.

\section{References}


Amarowicz R, Pegg RB, Rahimi-Moghaddam P, Barl B, Weil JA (2004) Free radical scavenging capacity and antioxidant activity of selected plant species from the Canadian prairies. Food Chem 84(4):551-562

Baeva E, Bleha R, Lavrova E, Sushytskyi L, Copíková J, Jablonsky I, Kloucek P, Synytsya A (2019) Polysaccharides from basidiocarps of cultivating mushroom Pleurotus ostreatus: isolation and structural characterization. Molecules 24(15):2740-2755

Bi SX, Huang WJ, Chen S, Huang CH, Li CL, Guo ZY, YangJN, Zhu JH, SongLY, Yu RM (2020) Cordyceps militaris polysaccharide converts immunosuppressive macrophages into M1-like phenotype and activates $\mathrm{T}$ lymphocytes by inhibiting the PD-L1/PD-1 axis between TAMs and T lymphocytes. Int J Biol Macromol 150:261-280

Bitter T, Muri HM (1962) A modified uronic acid carbazole reaction. Anal Chem 4(4):330-334

Blois MS (1958) Antioxidant determinations by the use of a stable free radical. Nature 181:1199-1200

Chaplin MF, Kennedy JF (1994) Carbohydrate analysis. London: Oxford University Press.

Chauveau C, Talaga P, Wieruszeski JM, Strecker G, Chavant L (1996) A water-soluble $\beta$-d-glucan from Boletus erythropus. Phytochemistry 43(2):413-415

Chen C, Wang ML, Jin C, Chen HJ, Li SH, Li SY, Dou XF, Jia JQ, Gui ZZ (2015) Cordyceps militaris polysaccharide triggers apoptosis and $G_{0} / G_{1}$ cell arrest in cancer cells. J Asia-Pac Entomol 18(3):433-438

Cheung JK, Li J, Cheung AW, Zhu Y, Zheng K Y, Bi CW, Duan R, Choi RCY, Lau DTW, Dong TTX, Lau BWC, Tsim KWK (2009) Cordysinocan, a polysaccharide isolated from cultured Cordyceps, activates immune responses in cultured T-lymphocytes and macrophages: signaling cascade and induction of cytokines. $J$ Ethnopharmacol 124(1):61-68 Chiu CH, Chyau CC, Chen CC, Lin CH, Cheng CH, Mong MC (2014) Polysaccharide extract of Cordyceps sobolifera attenuates renal injury in endotoxemic rats. Food Chem. Toxicol 69:281-288

Cui SW (2005) Food carbohydrates chemistry, physical properties, and applications. Boca Raton: Taylor \& Francis Group, CRC Press.

Fan ST, Nie SP, Huang XJ, Wang S, Hu JL, Xie JH, Nie QX, Xie MY (2018) Protective properties of combined fungal polysaccharides from Cordyceps sinensis and Ganoderma atrum on colon immune dysfunction. Int J Biol Macromol 114:1049-1055

Fisher M, Yang LX (2002) Anticancer effects and mechanisms of polysaccharide-K (PSK): implications of cancer immunotherapy. Anticancer Res 22(3):1737-1754

Friedman M (2016) Mushroom polysaccharides: chemistry and antiobesity, antidiabetes, anticancer, and antibiotic properties in cells, rodents, and humans. Foods 5(4):80-119 
Gondim DV, Costa JL, Rocha SS, Brito GAD, Ribeiro RD, Vale ML (2012) Antinociceptive and antiinflammatory effects of electroacupuncture on experimental arthritis of the rat temporomandibular joint. Can. J. Physiol. Pharm 90(11):395-405

Hu S, Wang J, Li F, Hou P, Yin J, Yang Z, Yang X, Li T, Xia B, Zhou G, Liu M, Song W, Guo S (2019) Structural characterisation and cholesterol efflux improving capacity of the novel polysaccharides from Cordyceps militaris. Int J Biol Macromol 131:264-272

Jin M, Zhang H, Wang J, Shao D, Yang H, Huang Q, Shi J, Xu C, Zhao K (2019) Response of intestinal metabolome to polysaccharides from mycelia of Ganoderma lucidum. Int J Biol Macromol 122:723-731

Kacurakova M, Capek P, Sasinkova V, Wellner N, Ebringerova A (2000) FT-IR study of plant cell wall model compounds: pectic polysaccharides and hemicelluloses. Carbohyd Polym 43(2):195-203

Kawai Y, Seno N, Anno K (1969) A modified method for chondrosulfatase assay. Anal Chem 32(2):314321

Kumar CG, Joo HS, Choi JW, Koo YM, Chang CS (2004) Purification and characterization of an extracellular polysaccharide from haloalkalophilic Bacillus sp I-450. Enzyme Microb Tech 34(7):673-681

Laskin DL (2009) Macrophages and inflammatory mediators in chemical toxicity: a battle of forces. Chem Res Toxicol 22(8):1376-1385

Leandro SM, Gil MC, Delgadillo I (2003) Partial characteriation of exopolysaccharides exudated by planktonic diatoms maintained in batch cultures. Acta Oecol 24(1):S49-55

Li RY, Zhang LN, Tang ZQ, Li TQ, Li GX, Zhang RL, Ge M (2019) Effects of fungal polysaccharide on oxidative damage and TLR4 pathway to the central immune organs in Cadmium intoxication in chickens. Biol Trace Elem Res 191:464-473

Liu RM, Dai R, Luo Y, Xiao JH (2019) Glucose-lowering and hypolipidemic activities of polysaccharides from Cordyceps taii in streptozotocin-induced diabetic mice. BMC Com Altern M 19:230-239

Malek TR (2008) The biology of interleukin-2. Annu Rev Immunol 26:453-479

Matthaei JH, Jones OW, Martin RG, Nirenberg MW (1962) Characteristics and composition of RNA coding units. PNAS 48:666-677

Meng LZ, Feng K, Wang LY, Cheong KL, Nie H, Zhao J, Li SP (2014) Activation of mouse macrophages and dendritic cells induced by polysaccharides from a novel Cordyceps sinensis fungus UM01. J Funct Foods 9:242-253

Methacanon P, Madla S, Kirtikara K, Prasitsil M (2005) Structural elucidation of bioactive fungi-derived polymers. Carbohyd Polym 60(2):199-203 
Rashid S, Unyayar A, Mazmanci MA, McKeown SR, Banat IM, Worthington J (2011) A study of anti-cancer effects of Funalia trogii in vitro and in vivo. Food Chem Toxicol 49(7):1477-1483

Schepetkin IA, Quinn MT (2006) Botanical polysaccharides: macrophage immunomodulation and therapeutic potential. Int Immunopharmacol 6(3):317-333

Seymour FR (1979) Correlation of the structure of dextran to their ${ }^{1} \mathrm{H}$ NMR spectra. Carbohyd Res 74(1):77-92

Shimizu D (1994) Color iconography of vegetable wasps and plant worms. Tokyo: Seibundo Shinkosha.

Shingel KI (2002) Determination of structural peculiarities of dexran, pullulan and $\gamma$-irradiated pullulan by Fourier-transform IR spectroscopy. Carbohyd Res 337(16):1445-1451

Snarr B, Qureshi S, Sheppard D (2017) Immune recognition of fungal polysaccharides. J Fungi 3(3):1-29

Sun HH, Mao WJ, Chen Y, Guo SD, Li HY, Qi XH (2009) Isolation, chemical characteristics and antioxidant properties of the polysaccharides from marine fungus Penicillium sp. F23-2. Carbohyd Polym 78(1):117124

Tang W, Eisenbrand G (1992) Chinese drugs of plant origin: chemistry, pharmacology and use in traditional and modern medicine. Berlin Heidelberg: Springer-Verlag.

Thambiraja SR, Phillips M, Koyyalamudi SR, Reddy N (2015) Antioxidant activities and characterisation of polysaccharides isolated from the seeds of Lupinus angustifolius. Ind Crop Prod 74:950-956

Uzochukwu S, Balog E, Loefler RT, Ngoddy PO (2002) Structural analysis by ${ }^{13} \mathrm{C}$-nuclear magnetic resonance spectroscopy of glucan extracted from natural palm wine. Food Chem 76(3):287-291

Vilcek J, Lee TH (1991) Tumor necrosis factor: new insights into the molecular mechanisms of its multiple actions. J Biol Chem 266(12):7313-7316

Wang Y, Liu D, Zhao H, Jiang HX, Luo C, Wang M, Yin HP (2014) Cordyceps sinensis polysaccharide CPS2 protects human mesangial cells from PDGF-BB-induced proliferation through the PDGF/ERK and TGF$\beta_{1} /$ Smad pathways. Mol Cell Endocrinol 382(2):979-988

Wasser SP (2010) Medicinal mushroom science: history, current status, future trends, and unsolved problems. Internat J Med Mushr 12(1):1-16

Wu FY, Yan H, Ma XN, Jia JQ, Zhang GZ, Guo XJ, Gui ZZ (2012) Comparison of the structural characterization and biological activity of acidic polysaccharides from Cordyceps militaris cultured with different media. World J Microb Biot 28:2029-2038 
Wu J, Zhou JX, Lang YG, Yao L, Xu H, Shi HB, Xu SD (2012) A polysaccharide from Armillaria mellea exhibits strong in vitro anticancer activity via apoptosis-involved mechanisms. Int J Biol Macromol 51(4):663-667

Xia YL, Luo FF, Shang YF, Chen PL, Lu YZ, Wang CS (2017) Fungal cordycepin biosynthesis is coupled with the production of the safeguard molecule pentostatin. Cell Chem Biol 24(12):1479-1489

Yang XL, Wang RF, Zhang SP, Zhu WJ, Tang J, Liu JF, Chen P, Zhang D, Ye W, Zheng Y (2014) Polysaccharides from Panax japonicus C.A. meyer and their antioxidant activities. Carbohyd Polym 101:386-391

Zhang GY, Yin QS, Han T, Zhao YX, Su JJ, Li MZ, Ling JY. 2015. Purification and antioxidant effect of novel fungal polysaccharides from the stroma of Cordyceps kyushuensis. Ind Crop Prod 69:485-491

Zhang QB, Qi M, Zhao TT, Deslandes E, Ismaeli NM, Molloy F, Critchley AT (2005) Chemical characteristics of a polysaccharide from Porphyra capensis (Rhodophyta), Carbohyd Res 340(15):24472450

Zhang ZF, Lv GY, Pan HJ, Pandey A, He WQ, Fan LF (2012) Antioxidant and hepatoprotective potential of endo-polysaccharides from Hericium erinaceus grown on tofu whey. Int J Biol Macromol 51(5):1140-1146

Zhao H, Wang QH, Sun YP, Yang BY, Wang ZB, Chai GF, Guan YZ, Zhu WG, ZP Shu, Lei X, Kuang HX (2014) Purification, characterization and immunomodulatory effects of Plantago depressa polysaccharides. Carbohyd Polym 112:63-72

\section{Figures}



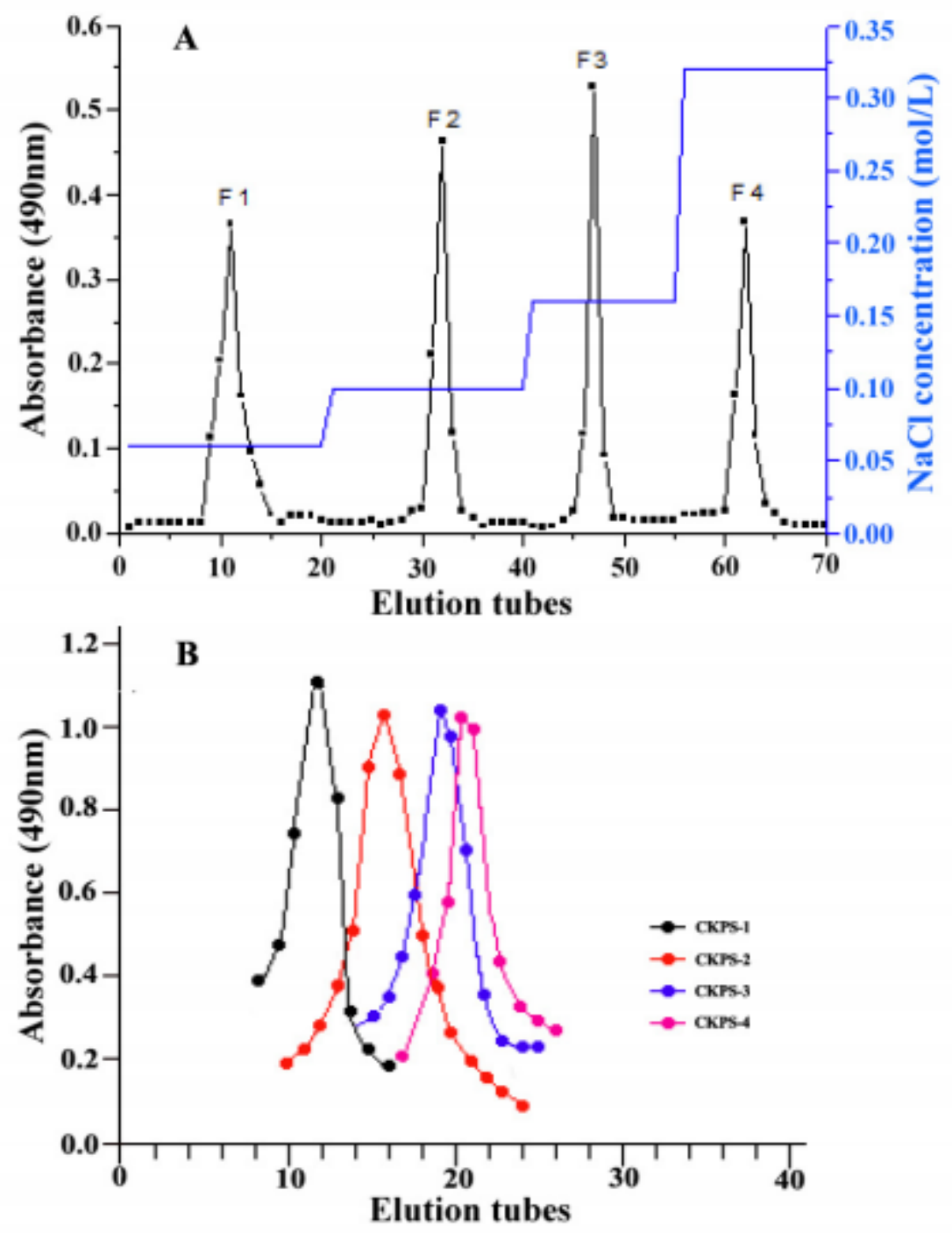

Figure 1

Separation and purification of polysaccharides of Cordyceps kyushuensis. (A) DE-23 chromatographic profile for CKPS eluted with different $\mathrm{NaCl}$ solution. (B) Sephadex G-150 chromatographic profile for CKPS eluted with water. 


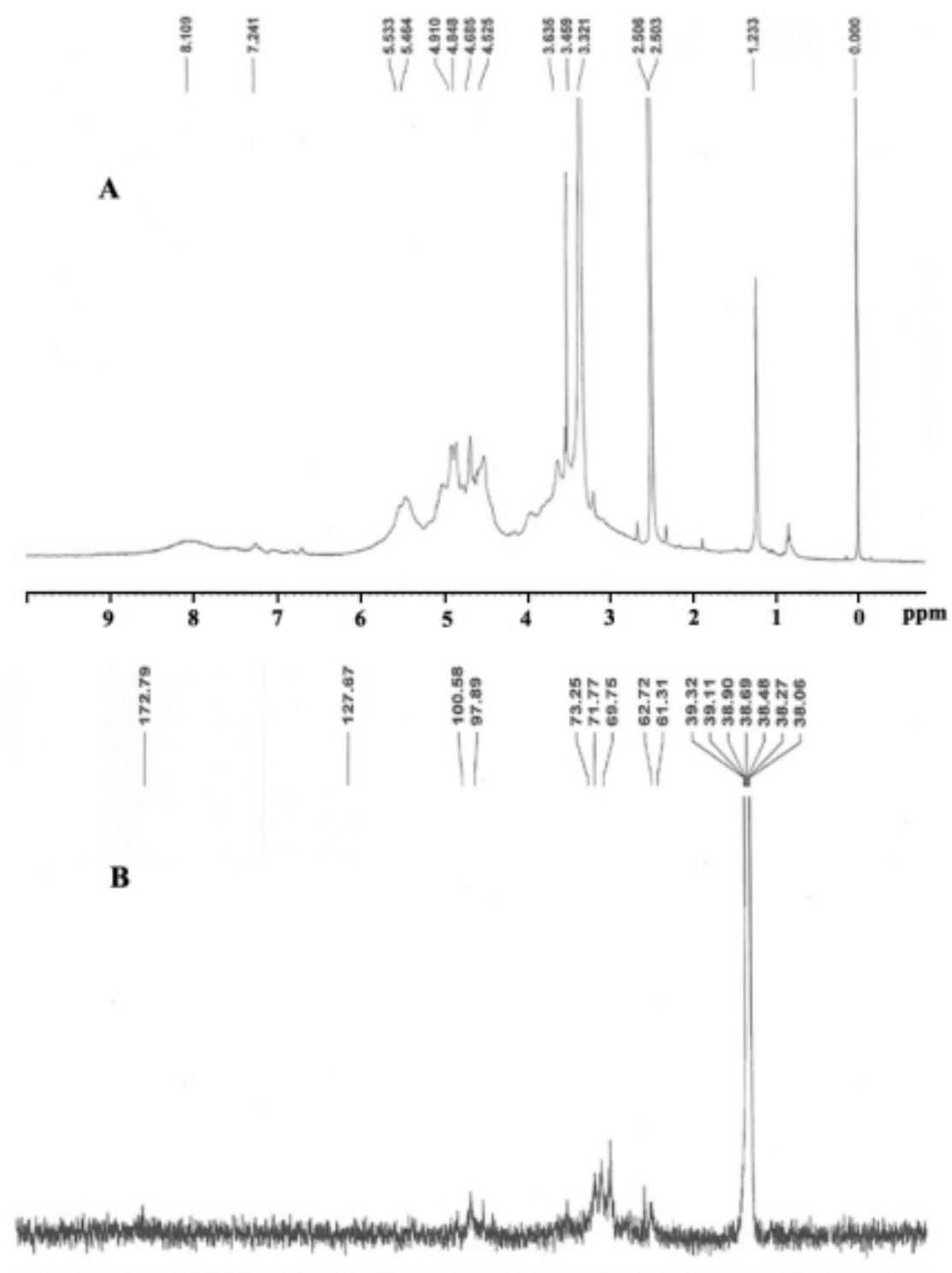

$\begin{array}{llllllllllllllllllll}190 & 180 & 170 & 160 & 150 & 140 & 130 & 120 & 110 & 100 & 90 & 80 & 70 & 60 & 50 & 40 & 30 & 20 & 10 & \text { ppm }\end{array}$

Figure 2

1H NMR spectra (A) and 13C NMR spectra (B) of the purified CKPS-1 of Cordyceps kyushuensis.. 

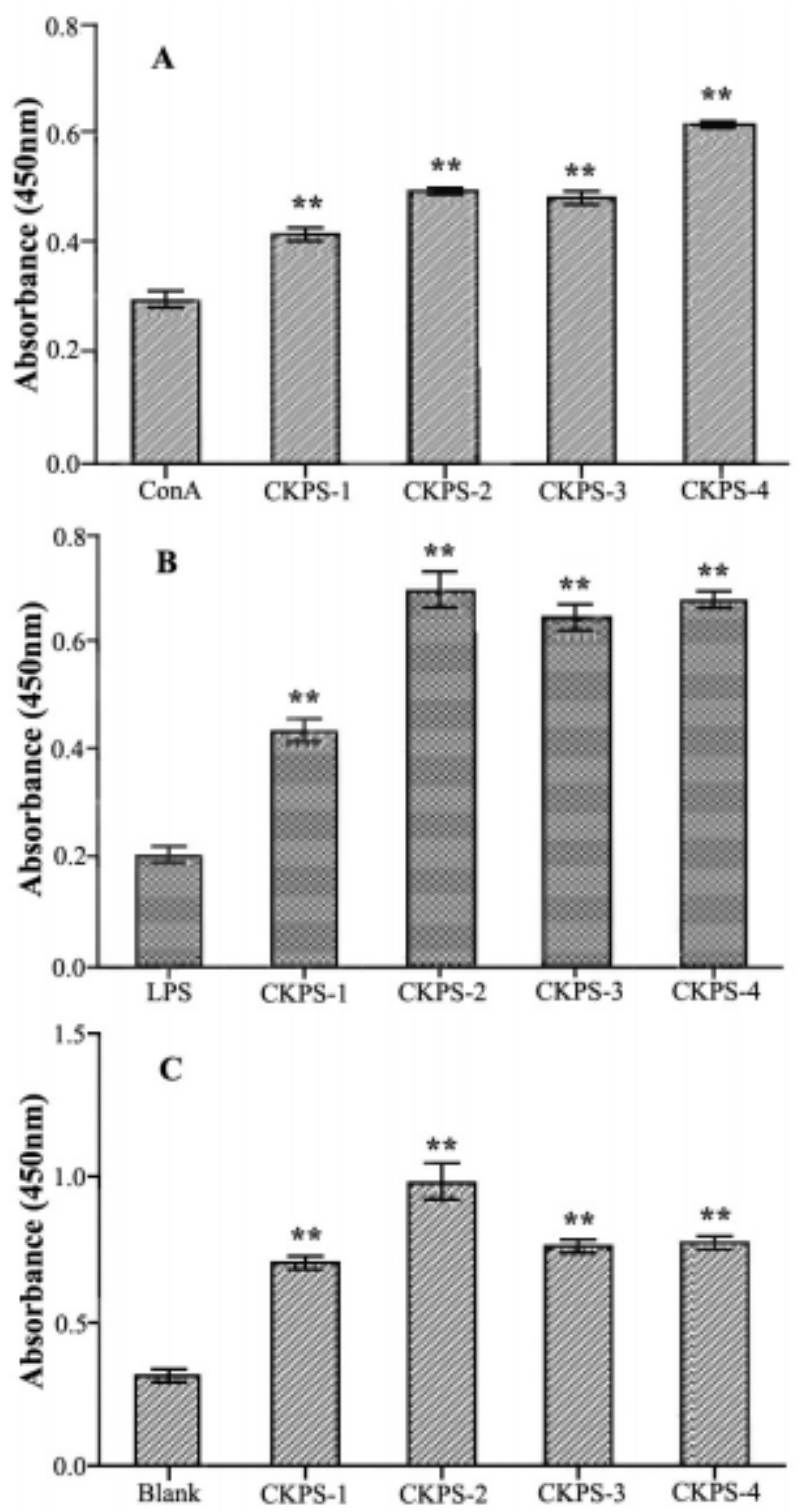

Figure 3

Splenocyte proliferation of polysaccharide fractions with mitogens (A) ConA, (B) LPS, or without (C) in vivo. Values are means \pm S.D. $(n=3)$. ${ }^{*} p<0.01$ vs. control. 

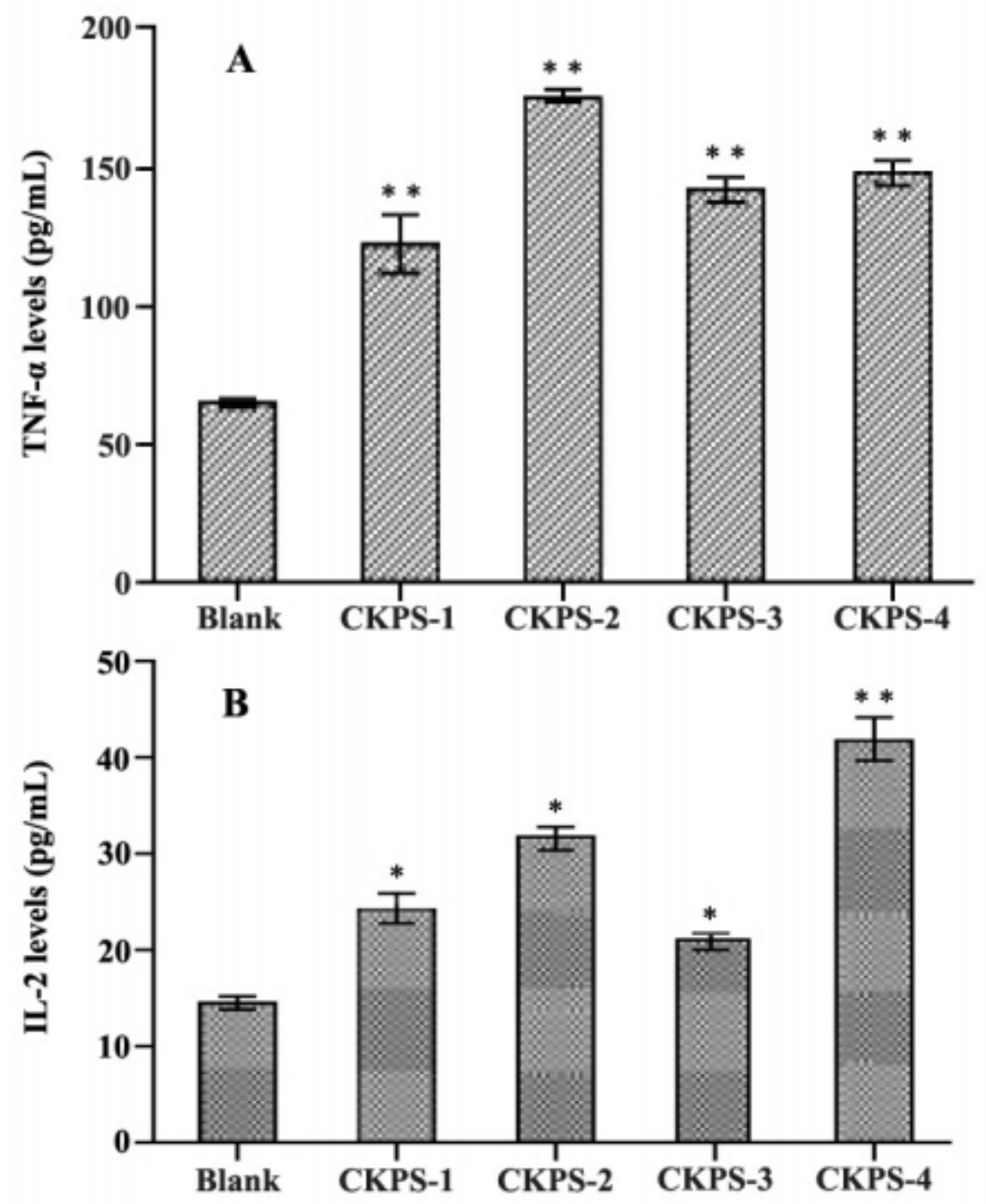

Figure 4

Effects of polysaccharide fractions on levels of serum TNF-a (A) and IL-2 (B) in mice. Values are means \pm S. D. $(n=3) .{ }^{*} p<0.05,{ }^{*} p<0.01$ vs. control. 


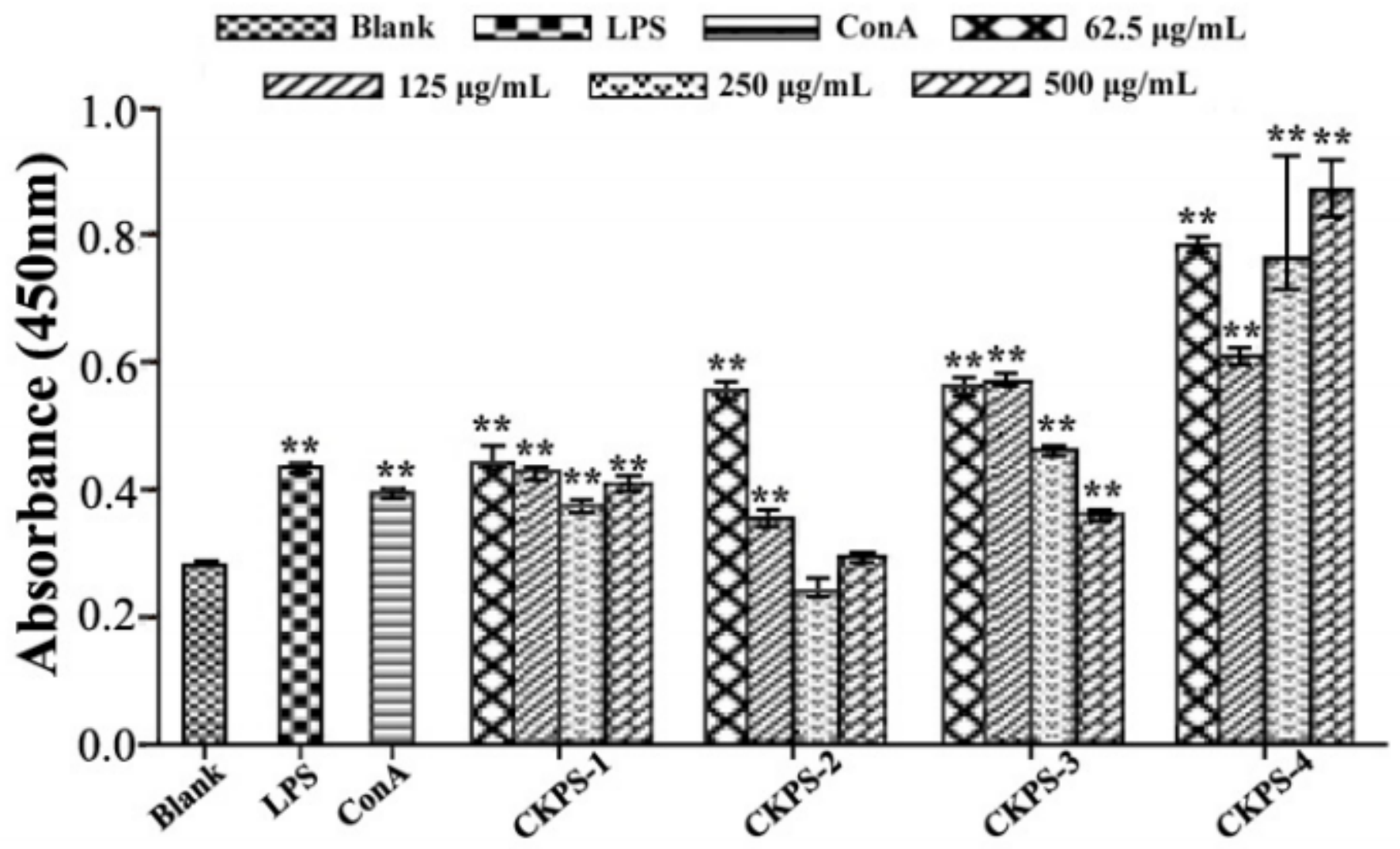

Figure 5

Splenocyte proliferation of polysaccharide fractions in vitro. Values are means \pm S.D. $(n=3) .{ }^{\star \star} p<0.01$ vs. control. 


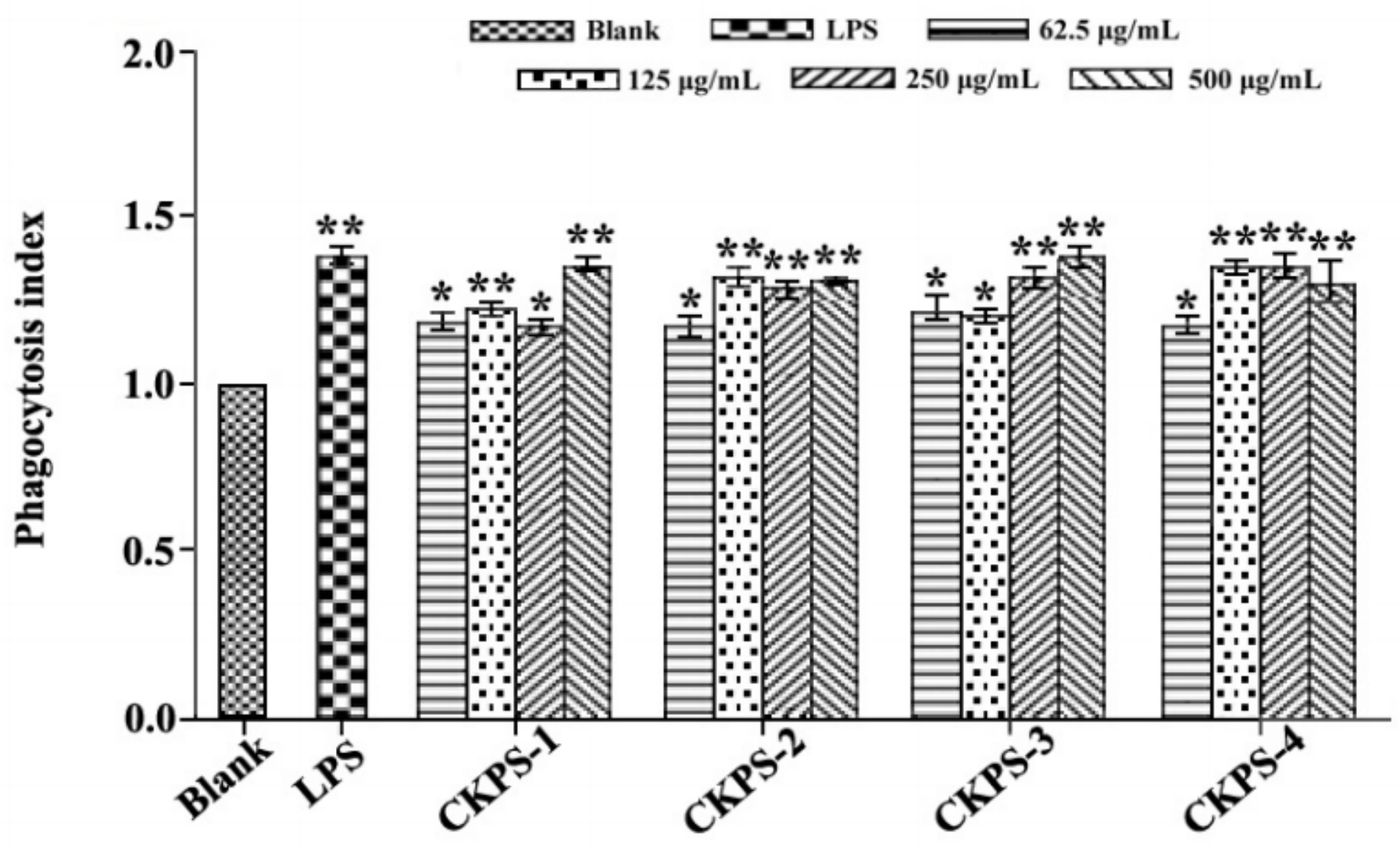

Figure 6

Macrophage phagocytosis of polysaccharide fractions and LPS by neutral red uptake assay. Values are means \pm S. D. $(n=3) .{ }^{*} p<0.05,{ }^{\star *} p<0.01$ vs. control. 

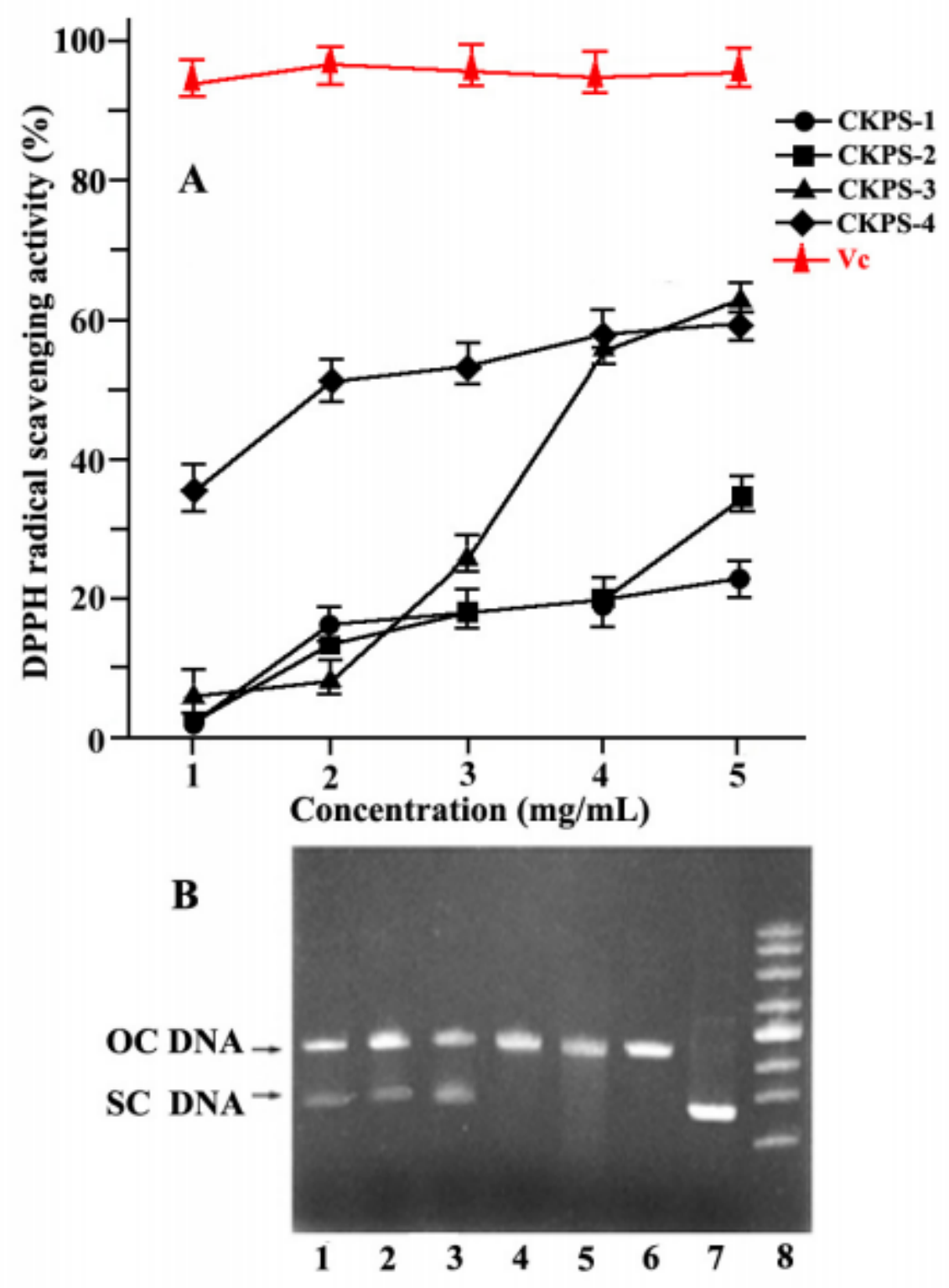

Figure 7

Evaluation of antioxidant activity of polysaccharides extracted from Cordyceps kyushuensis. (A) Scavenging activity on DPPH radical of polysaccharide fractions from Cordyceps kyushuensis. Values are means \pm S.D. $(n=3)$. (B) Effects of polysaccharide fractions on protection of supercoiled DNA (plasmid pUC19). Lanes 1-5, H2O2+UV treated with rutin, CKPS 1-4, respectively; Lane 6, H2O2+UV treated without polysaccharide; Lane 7, untreated DNA (control); Lane 8, Supercoiled DNA marker. 